\title{
Anti-Müllerian hormone as a predictor of polycystic ovary syndrome treated with clomiphene citrate
}

\author{
Andon Hestiantoro, Yuwono Sri Negoro, Yohana Afrita, Budi Wiweko, Kanadi Sumapradja, Muharam Natadisastra \\ Division of Reproductive Immunoendocrinology, Department of Obstetrics and Gynecology, Faculty of Medicine, University of Indonesia/Cipto \\ Mangunkusumo Hospital, Jakarta, Indonesia
}

Objective: This study aimed to determine the threshold of anti-Müllerian hormone (AMH) as predictor of follicular growth failure in polycystic ovary syndrome (PCOS) patients treated with clomiphene citrate (CC).

Methods: Fifty female subjects with PCOS were recruited and divided into two groups based on successful and unsuccessful follicular growth. Related variables such as age, infertility duration, cigarette smoking, use of Moslem hijab, sunlight exposure, fiber intake, body mass index, waist circumference, AMH level, 25-hydroxy vitamin D level, and growth of dominant follicles were obtained, assessed, and statistically analyzed.

Results: The AMH levels of patients with successful follicular growth were significantly lower $(p=0.001)$ than those with unsuccessful follicular growth $(6.10 \pm 3.52$ vs. $10.43 \pm 4.78 \mathrm{ng} / \mathrm{mL})$. A higher volume of fiber intake was also observed in the successful follicular growth group compared to unsuccessful follicular growth group $(p=0.001)$. Our study found the probability of successful follicle growth was a function of AMH level and the amount of fiber intake, expressed as $\mathrm{Y}=-2.35+(-0.312 \times \mathrm{AMH}$ level) $+(0.464 \times$ fiber intake) (area under the curve, $0.88 ; 95 \%$ confidence interval, $0.79-0.98 ; p<0.001$ ).

Conclusion: The optimal threshold of AMH level in predicting the failure of follicle growth in patients with PCOS treated with CC was $8.58 \mathrm{ng} / \mathrm{mL}$.

Keywords: Anti-Müllerian hormone; Clomiphene citrate; Ovarian follicle; Polycystic ovary syndrome

\section{Introduction}

Polycystic ovary syndrome (PCOS) is found in $5 \%$ to $6 \%$ of women of reproductive age. It affects women's reproductive capability; thus patients have risks of infertility, miscarriage, and complicated pregnancy. A study revealed that the prevalence of oligoovulation or anovulation in patients with PCOS ranged from $65 \%$ to $80 \%$ [1]. The most common complaint reported by patients with PCOS was infertility due to chronic anovulation.

Ovarian stimulation followed by ovulation induction is an approach

Received: Feb 23, 2016 · Revised: Aug 12, 2016 • Accepted: Aug 12, 2016 Corresponding author: Andon Hestiantoro

Division of Reproductive Immunoendocrinology, Department of Obstetrics and Gynecology, Faculty of Medicine, University of Indonesia/Cipto Mangunkusumo Hospital, Jl. Diponegoro No. 71, Jakarta 10430, Indonesia

Tel: +62-21-3928720 Fax: +62-21-3928719 E-mail: hestiantoro@gmail.com

This is an Open Access article distributed under the terms of the Creative Commons Attribution Non-Commercial License (http://creativecommons.org/licenses/by-nc/4.0/) which permits unrestricted non-commercial use, distribution, and reproduction in any medium, provided the original work is properly cited. to promote fertility in patients with PCOS [2]. Several methods for this approach have been studied, such as body weight reduction, clomiphene citrate (CC) or gonadotropin administration, and diathermic laparoscopy. Currently, the first-line procedure for ovarian stimulation in patients with PCOS and anovulation is $\mathrm{CC}$ treatment [3]. This strategy was reported to be effective in $80 \%$ of women with type 2 ovulation; about $50 \%$ of women experienced pregnancy after six cycles of administration [1]. In women with successful ovulation induction, occurrence of ovulation was about $71 \%$ after the first cycle (50 $\mathrm{mg}$ dose), $28 \%$ after the second cycle (100 $\mathrm{mg}$ dose), and $6 \%$ after the third cycle (150 mg dose) [4]. The reported failure rate of ovulation induction in several studies ranged from about $15 \%$ to $25 \%$ [5]. Ovulation induction failure is defined as the ineffectiveness of $\mathrm{CC}$ at the dose of $100 \mathrm{mg}$ or more to induce ovulation, commonly stated as "CC resistant" [6].

Ovulation induction failure associated with CC often occurs in patients with obesity, insulin resistance, hyperandrogenism, and amenorrhea. Patients unresponsive to CC therapy are usually discovered 
after 3 to 6 months of treatment [4]. If the success rate in patients could be predicted at an earlier time point, then there would be additional time for gynecologists to replace $\mathrm{CC}$ with alternative therapeutic modalities, such as gonadotropin or laparoscopy $[4,5]$. Factors predicting a successful ovulation with CC treatment include body mass index (BMI), hyperandrogenemia, and age in a nomogram [6]. Ovarian volume and menstrual status are additional factors in predicting the therapeutic response of CC [5]. The ratio of fasting blood glucose level to fasting insulin level could be the marker of CC resistance [7].

As an important regulator in the ovary, anti-Müllerian hormone (AMH) is suspected to affect $\mathrm{CC}$ resistance [8]. The specific patterns of expression in the ovary indicate that $\mathrm{AMH}$ may play a role during follicle development and function [9]. Produced predominantly by granulosa cells of the preantral and small antral follicles, AMH inhibits follicle recruitment as well as follicle growth and selection dependent on follicle-stimulating hormone (FSH), and also attenuates the FSHdependent increase of aromatase activity during early follicle development [8]. In addition, AMH has an important role in the ovarian follicular microenvironment associated with ovarian folliculogenesis [10], and AMH showed positive correlation with ovarian sensitivity to FSH [8].

The role of AMH in follicle development was confirmed in a study demonstrating that continuous low dose recombinant FSH administration significantly lowered the $\mathrm{AMH}$ level in follicles. A decline of AMH level interrupted the inhibition mechanism in the follicles; therefore they could develop as mature follicles [11]. Previous studies reported that $\mathrm{AMH}$ could also be useful in the prediction of ovarian response to CC in obese women with anovulation [12]. Additional studies to determine the most useful clinical value of the hormone level were needed. This study was conducted to define the threshold of the AMH level as a predictor of follicular growth failure in patients with PCOS treated with CC.

\section{Methods}

\section{Study design}

This cross-sectional observational study was conducted in the Endocrinology and Gynecology Clinic in Cipto Mangunkusumo Hospital from June 2013 to April 2014. This study included 50 female subjects with PCOS who were infertile, willing to participate in this study, and had not been under either $\mathrm{CC}$ or metformin therapy within the previous 3 months. The Rotterdam consensus was used to exclude subjects without PCOS, although we did not check the level of cortisol, thyroid-stimulating hormone (TSH), and insulin in these patients. Diagnosis of PCOS was based on the Rotterdam consensus criteria (two or three of the following criteria: oligoovulation or anovulation, hyperandrogenemia, and ultrasonographic appearance of polycystic ovaries). We predominantly found oligoovulation or anovulation in our study, and the ultrasonographic appearance of polycystic ovaries, whereas hyperandrogenemia was quite rare. We excluded patients with incomplete data. Subjects were recruited using the consecutive sampling method. This study assessed several variables, which consisted of the age of patient, duration of infertility, cigarette smoking exposure, use of Moslem hijab, sun exposure, fiber intake, BMI, waist circumference, AMH level, 25-hydroxy (25-OH) vitamin D level, and follicular growth. BMI was classified based on the World Health Organization criteria for Asians, where BMI $>23.0 \mathrm{~kg} / \mathrm{m}^{2}$ is overweight [13]. Anamnesis, physical examination, and transvaginal ultrasonography (TVU) were performed on the eligible study subjects. Venous blood samples were taken to measure serum levels of AMH (AMH Gen II ELISA; Beckman Coulter, Fullerton, CA, USA) and 25-OH vitamin $D$ (chemiluminescent immunoassay method, Liaison $25 \mathrm{OH}$ vitamin D total assay; DiaSorin, Stillwater, MN, USA). CC, at the dose of $100 \mathrm{mg}$ daily, was provided to the subjects to be taken for 5 days starting from day 2 of their spontaneous periods or after progestin-withdrawal bleeding. Follicular growth assessment by TVU was performed at day 12 of the menstrual period. Successful and unsuccessful follicular growth was compared according to the subjects' respective AMH levels. These values were entered into a diagnostic test using statistical analysis and the receiver operating characteristic (ROC) curve. Dietary intake assessment using a 24-hour food recall method was taken by a designated trained interviewer to collect data concerning the amount of daily fiber intake. Analysis on fiber intake was made using the NutriSurvey software program (NutriSurvey for Windows, J. Erhardt, University of Indonesia, Jakarta, Indonesia; http://www.nutrisurvey.de).

\section{Inclusion and exclusion criteria}

The inclusion criteria were women $<40$ years, who had been previously diagnosed with PCOS based on Rotterdam consensus criteria (two or three criteria: oligoovulation or anovulation, hyperandrogenemia, and sonographic appearance of polycystic ovaries), had been infertile, were willing to participate in this study, and had not consumed any medications (CC or metformin) within 3 months. We excluded patients with incomplete data.

\section{Outcome measures}

Primary study outcomes were follicle growth and the threshold level of AMH as a predictor of unsuccessful follicular growth. Successful follicular growth was defined as the presence of one (or more) dominant follicle with a diameter of no less than $17 \mathrm{~mm}$ on TVU at day 11 or day 12 of the menstrual period. The secondary outcome was to find a linear function to predict the success (or failure) of follicle 
growth by analyzing several patient factors such as age, duration of infertility, cigarette exposure, use of Moslem hijab, sun exposure, fiber intake, BMI, waist circumference, and serum $\mathrm{AMH}$ and $25-\mathrm{OH}$ vitamin D levels.

\section{Statistical analysis}

Data were analyzed using the SPSS ver. 17.0 (SPSS Inc., Chicago, IL, USA). Valid data were transformed into a distribution table to calculate the means, medians, and the distributions. To determine the threshold level of $\mathrm{AMH}$, statistical analysis and the ROC curve were used. The level of significance $a=0.05$ was used. Multivariate analysis was established using the binary logistic regression test. Bivariate analysis was done between follicular growth and each of the following variables: age, BMI, waist circumference, $\mathrm{AMH}$ level and $25-\mathrm{OH}$ vitamin D level, and the amount of fiber intake. Only variables that showed significant correlation ( $p$-value $<0.25$ ) with follicular growth were used for further multivariate analysis.

\section{Ethics approval}

The study protocol was approved by Ethics Committee of Faculty of Medicine University of Indonesia and Cipto Mangunkusumo Hospital, with Ethical Clearance reference number of 287/H2.F1/ETIK/2013. All participants had been informed and provided written consent prior to enrollment.

\section{Results}

The 50 female subjects with PCOS enrolled this study were divided into two groups based on the assessment of follicular growth. Twen- ty-three subjects (46\%) had successful follicular growth and 27 subjects (56\%) had unsuccessful follicular growth. Subject characteristics were women of reproductive age (mean \pm standard deviation [SD], $29.66 \pm 5.08$ years) with BMI $24.81 \mathrm{~kg} / \mathrm{m}^{2}$ (range, 22.23-28.71), and had experienced 4 years (range, 1.25-6.00) of infertility. The mean value of the $\mathrm{AMH}$ level was around $7.51 \mathrm{ng} / \mathrm{mL}$, fiber intake was around $9.57 \mathrm{~g}, 25-\mathrm{OH}$ vitamin D was around $9.50 \mathrm{ng} / \mathrm{mL}$, and waist circumference was around $85.14 \mathrm{~cm}$. Some subjects wore Moslem hijab, had <60 minutes sun exposure, and had no cigarette expo-

Table 1. Subject characteristics

\begin{tabular}{lc}
\hline Characteristics & Value $(\mathrm{n}=50)$ \\
\hline Age $(\mathrm{yr})$ & $29.66 \pm 5.08$ \\
$\mathrm{BMI}\left(\mathrm{kg} / \mathrm{m}^{2}\right)$ & $24.81(22.23-28.71)$ \\
$\mathrm{AMH}$ level $(\mathrm{ng} / \mathrm{mL})$ & $7.51(6.20-8.88)$ \\
Infertility duration $(\mathrm{yr})$ & $4(1.25-6.00)$ \\
$25-\mathrm{OH}$ vitamin D level $(\mathrm{ng} / \mathrm{mL})$ & $9.50(7.70-12.75)$ \\
Fiber intake $(\mathrm{g})$ & $9.57 \pm 3.02$ \\
Waist circumference $(\mathrm{cm})$ & $85.14 \pm 9.98$ \\
Use of Moslem hijab & \\
Yes & $29(58.0)$ \\
No & $21(42.0)$ \\
Sun exposure & \\
$<60$ min & $46(92.0)$ \\
$>60$ min & $4(8.0)$ \\
Cigarette smoking & \\
Yes & $20(40.0)$ \\
No & $30(60.0)$
\end{tabular}

Values are presented as mean \pm standard deviation, median (range), or number (\%).

BMI, body mass index; $\mathrm{AMH}$, anti-Müllerian hormone; 25-OH, 25-hydroxy.

Table 2. Bivariate analysis of the variables and comparison of AMH level between groups

\begin{tabular}{|c|c|c|c|c|c|}
\hline \multirow{2}{*}{ Characteristics } & \multicolumn{2}{|c|}{ Ovulation status } & \multirow{2}{*}{ Mean differences ( $\mathrm{Cl}$ 95\%) } & \multirow{2}{*}{$p$-value } & \multirow{2}{*}{ AUC $(95 \% \mathrm{Cl})$} \\
\hline & Successful & Unsuccessful & & & \\
\hline Age (yr) & $29.65 \pm 4.82$ & $29.67 \pm 5.38$ & 0.21 (-2.94 to 2.91$)$ & $0.99^{\mathrm{a})}$ & - \\
\hline $\mathrm{BMI}\left(\mathrm{kg} / \mathrm{m}^{2}\right)$ & $24.74 \pm 4.02$ & $26.76 \pm 6.44$ & $-2.01(-5.13$ to 1.10$)$ & $0.20^{\mathrm{a})}$ & - \\
\hline Infertility duration (yr) & 3.57 (2.50 to 4.83$)$ & 3.68 (2.60 to 4.95$)$ & $-0.00(-0.45$ to 0.46$)$ & $0.98^{\mathrm{b})}$ & - \\
\hline $25-\mathrm{OH}$ vitamin D level ( $\mathrm{ng} / \mathrm{mL})$ & $11.20 \pm 4.48$ & $11.08 \pm 5.13$ & $0.12(-2.64$ to 2.88$)$ & $0.93^{\mathrm{a})}$ & - \\
\hline Waist circumference $(\mathrm{cm})$ & $83.22 \pm 7.13$ & $86.78 \pm 11.77$ & 2.72 (1.16 to 4.28$)$ & $0.21^{\mathrm{a})}$ & - \\
\hline Fiber intake (g) & $11.20 \pm 2.68$ & $8.47 \pm 2.77$ & 2.72 (1.16 to 4.28$)$ & $0.001^{\mathrm{a})}$ & - \\
\hline AMH level (ng/mL) & $6.10 \pm 3.52$ & $10.43 \pm 4.78$ & $-4.31(-6.74$ to -1.89$)$ & $0.001^{\mathrm{a})}$ & $0.75(0.62 \text { to } 0.88)^{a}$ \\
\hline Use of Moslem hijab & & & $0.668(0.386$ to 1.156$)$ & $0.152^{\mathrm{c})}$ & - \\
\hline Yes & $12(48.0)$ & $17(68.0)$ & & & \\
\hline No & $13(52.0)$ & $8(32.0)$ & & & \\
\hline Cigarette smoking & & & $0.583(0.300$ to 1.134$)$ & $0.083^{c)}$ & - \\
\hline Yes & $7(28.0)$ & $13(52.0)$ & & & \\
\hline No & $18(72.0)$ & $12(48.0)$ & & & \\
\hline
\end{tabular}

Values are presented as mean \pm standard deviation, median (range), or number (\%).

$\mathrm{AMH}$, anti-Müllerian hormone; $\mathrm{Cl}$, confidence interval; $\mathrm{AUC}$, area under the curve; $\mathrm{BMI}$, body mass index; 25-OH, 25-hydroxy.

Statistical comparisons were performed between groups: ${ }^{a}$ Unpaired $t$-test on the original data; ${ }^{b}$ Unpaired $t$-test on square root transformed data; ${ }^{\circ} C h i-s q u a r e ~ t e s t$. 
sure. The details of subject characteristics are shown in Table 1.

\section{Association of AMH level and follicular growth}

The mean AMH level was significantly lower $(p=0.001)$ in the successful follicular growth group (mean \pm SD, $6.10 \pm 3.52 \mathrm{ng} / \mathrm{mL}$ ) compared to that observed in the unsuccessful follicular growth group (mean \pm SD, $10.43 \pm 4.78 \mathrm{ng} / \mathrm{mL}$ ) (Table 2).

The area under the curve (AUC) showed that AMH level had moderate capacity as the predictor of follicle growth failure (Figure 1).

Using the ROC curve, we found the threshold of AMH level for predicting the failure of follicle growth was $8.58 \mathrm{ng} / \mathrm{mL}$, with a sensitivity of $78 \%$ and specificity of $67 \%$.

\section{Follicular growth as a function of AMH level and fiber intake}

An AMH level in the successful follicular growth group was $6.10 \pm 3.52$ $\mathrm{ng} / \mathrm{mL}$ and it was found to be significantly lower $(p=0.001)$ compared to that observed in unsuccessful follicular growth group (10.43 \pm 4.78
ROC curve

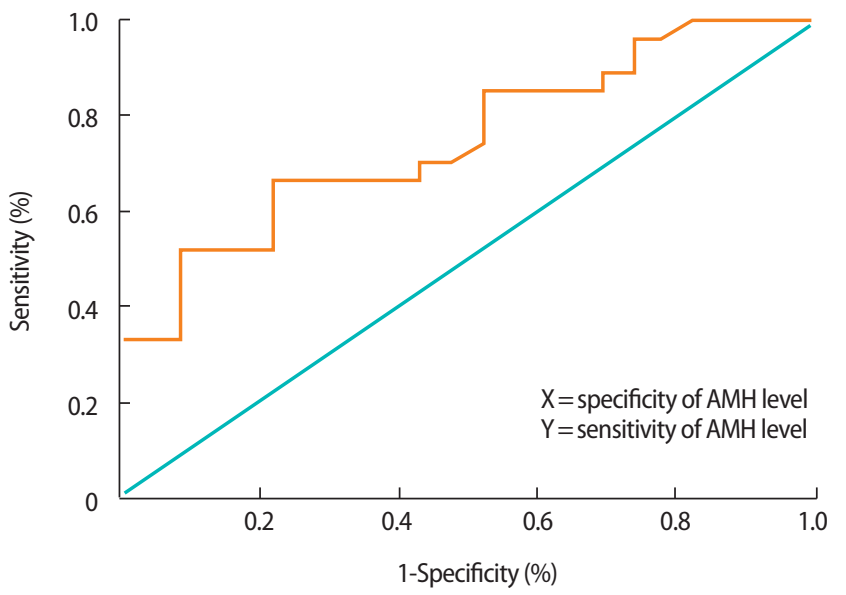

Figure 1. Based on the receiver operating characteristic (ROC) curve, anti-Müllerian hormone (AMH) levels had the highest area under the curve at 0.75 (95\% confidence interval of 0.62-0.88).

Table 3. Logistic regression model to predict successful follicular growth

\begin{tabular}{|c|c|c|c|c|c|c|c|c|}
\hline Variable & B & SE & Wald & df & $p$-value & Exponential (B) & \multicolumn{2}{|c|}{$95 \% \mathrm{Cl}$} \\
\hline \multicolumn{9}{|l|}{ Step 1} \\
\hline Moslem hijab & 1.035 & 0.898 & 1.331 & 1 & 0.249 & 2.816 & 0.485 & 16.361 \\
\hline AMH level & -0.292 & 0.124 & 5.494 & 1 & 0.019 & 0.747 & 0.585 & 0.953 \\
\hline Fiber intake & 0.429 & 0.173 & 6.150 & 1 & 0.013 & 1.536 & 1.094 & 2.157 \\
\hline BMI & 0.066 & 0.126 & 0.269 & 1 & 0.604 & 1.068 & 0.833 & 1.368 \\
\hline Constant & 2.055 & 4.485 & 0.210 & 1 & 0.647 & 7.809 & - & - \\
\hline \multicolumn{9}{|l|}{ Step 2} \\
\hline Moslem hijab & 0.881 & 0.853 & 1.066 & 1 & 0.302 & 2.413 & 0.453 & 12.839 \\
\hline Cigarette smoking & 0.934 & 0.863 & 1.172 & 1 & 0.279 & 2.545 & 0.469 & 13.808 \\
\hline AMH level & -0.288 & 0.122 & 5.565 & 1 & 0.018 & 0.750 & 0.59 & 0.952 \\
\hline Fiber intake & 0.416 & 0.170 & 5.973 & 1 & 0.015 & 1.515 & 1.086 & 2.115 \\
\hline Cigarette smoking & 0.640 & 0.775 & 0.682 & 1 & 0.409 & 1.897 & 0.415 & 8.666 \\
\hline AMH level & -0.314 & 0.122 & 6.603 & 1 & 0.010 & 0.730 & 0.575 & 0.928 \\
\hline Fiber intake & 0.431 & 0.174 & 6.144 & 1 & 0.013 & 1.539 & 1.094 & 2.163 \\
\hline Waist circumference & -0.051 & 0.040 & 1.612 & 1 & 0.204 & 0.951 & 0.879 & 1.028 \\
\hline Constant & 2.108 & 4.092 & 0.265 & 1 & 0.606 & 8.234 & - & - \\
\hline \multicolumn{9}{|l|}{ Step 4} \\
\hline AMH level & -0.337 & 0.122 & 7.615 & 1 & 0.006 & 0.714 & 0.562 & 0.907 \\
\hline Fiber intake & 0.429 & 0.175 & 6.027 & 1 & 0.014 & 1.536 & 1.09 & 2.163 \\
\hline Waist circumference & -0.054 & 0.039 & 1.881 & 1 & 0.170 & 0.948 & 0.878 & 1.023 \\
\hline Constant & 2.823 & 3.983 & 0.502 & 1 & 0.478 & 16.827 & - & - \\
\hline
\end{tabular}

$\mathrm{SE}$, standard error; df, degrees of freedom; $\mathrm{Cl}$, confidence interval; $\mathrm{AMH}$, anti-Müllerian hormone; $\mathrm{BMI}$, body mass index. 
Table 4. AMH threshold determination based on the AUC and probability

\begin{tabular}{cccc}
\hline AMH level $(\mathrm{ng} / \mathrm{mL})$ & Sensitivity (\%) & Specificity (\%) & Probability (\%) \\
\hline 3.40 & 22 & 96 & 77 \\
4.40 & 35 & 85 & 71 \\
5.10 & 48 & 81 & 67 \\
6.45 & 52 & 70 & 57 \\
7.46 & 70 & 67 & 49 \\
8.58 & 78 & 67 & 40 \\
9.44 & 78 & 59 & 34 \\
10.20 & 78 & 52 & 29 \\
\hline
\end{tabular}

$\mathrm{AMH}$, anti-Müllerian hormone; AUC, area under the curve.

$\mathrm{ng} / \mathrm{mL}$ ). The successful follicular growth group showed significant higher fiber intake $(11.20 \pm 2.68 \mathrm{~g})$ than that observed in unsuccessful follicular growth group $(8.47 \pm 2.77 \mathrm{~g})$, with $p$-value, 0.001 (Table 2).

Based on the correlation test, eligible variables for the logistic regression test were BMI, waist circumference, AMH level, fiber intake, use of Moslem hijab, and cigarette exposure. Binary logistic regression test was performed to determine the probability of having successful follicular growth with CC treatment (Table 3), resulting in the following function (Formula 1):

$Y=-2.35+(-0.312 \times$ AMH level $)+(0.464 \times$ fiber intake $)$

with the probability formulation $=\frac{1}{1+e^{-y}}$

The discriminating capability of the formulation according to the AUC is 0.88 (95\% confidence interval [Cl] of $0.79-0.98$ ) with $p<0.001$.

Determination of threshold value was based on the sensitivity and specificity. The threshold of AMH level found in this study was 8.58 $\mathrm{ng} / \mathrm{mL}$, and it had a moderately high specificity (67\%) and sensitivity (78\%), although it only contributed $40 \%$ towards predicting failure of follicular growth according to Formula 1 (Table 4).

\section{Discussion}

This study was conducted in female subjects with PCOS receiving CC treatment (dose of $100 \mathrm{mg}$ ) and observed for successful or unsuccessful follicular growth. The successful follicular growth rate in subjects with CC treatment found in this study was $46 \%$ (Table 2), which is consistent with rates $(40 \%-80 \%)$ reported in a previous study by Messinis and Milingos [14] .

\section{Association of AMH level and follicular growth}

The mean level of AMH in subjects with PCOS was $7.51 \mathrm{ng} / \mathrm{mL}$ (6.20-8.88) (Table 1). Previous studies in patients with PCOS by Li et al. [15] reported a mean AMH level of $9.85 \mathrm{ng} / \mathrm{mL}$ while Catteau-Jonard et al. [11] reported $6.59 \mathrm{ng} / \mathrm{mL}$. Piltonen et al. [16] concluded that the AMH level in patients with PCOS was always two or three times higher than the normal population (16-44 years). In alignment with these reports, meta-analysis by lliodromiti et al. [17] revealed higher AMH levels in patients with PCOS than in the normal population, thus the AMH level could be used for diagnosing PCOS, with $79 \%$ sensitivity and $83 \%$ specificity. A study by Sahmay et al. [18] reported a similar result with the AMH level $\geq 3.9 \mathrm{ng} / \mathrm{mL}$ as the cut-off to diagnose PCOS.

The AMH level in the successful follicle growth group was significantly lower $(p=0.001)$ than that of the unsuccessful follicle growth group (Table 2). The AMH level demonstrated a negative correlation with the probability of having a successful follicular growth. This finding concurs with that reported in a previous study by Amer et al. [19], which compared the AMH level in PCOS patients who underwent laparoscopic ovarian diathermy. The AMH level in the ovulation and anovulation groups were significantly different; the level was higher in the anovulation group ( $p=0.002)$ [19]. Mahran et al. [20] investigated 187 ovulation induction cycles with $\mathrm{CC}$ and revealed higher AMH levels in the anovulation group $(p<0.001)$ than in the ovulation group. di Clemente et al. [21] elaborated the inhibitory mechanism of AMH in the ovulatory process through its effect on specific type II receptors in granulosa and theca cells, in reducing the aromatase enzyme activity and luteinizing hormone receptors in FSH-stimulated granulosa cells, and in interfering with testosterone production by theca cells.

\section{Predictor of follicular growth failure}

This study aimed to determine the threshold of AMH level as the predictor of follicular growth failure in patients with PCOS treated with CC by using the ROC curve analysis. Based on the result of ROC curve, AMH level had a high AUC and a significant difference between groups $(0.75, p=0.001)$, with $8.58 \mathrm{ng} / \mathrm{mL}$ as the threshold with $78 \%$ sensitivity and $67 \%$ specificity. This finding indicates that PCOS patients with AMH level of $<8.58 \mathrm{ng} / \mathrm{mL}$ had twofold probability of having a successful follicular growth compared to patients with higher ( $\geq 8.58 \mathrm{ng} / \mathrm{mL}$ ) AMH level.

There were two other, similar studies that attempted to determine the threshold of AMH level. Mahran et al [20]. reported an AUC of $0.809(p<0.001)$ for $3.4 \mathrm{ng} / \mathrm{mL}$ threshold with $73 \%$ sensitivity and 78\% specificity, and Amer et al. [19] demonstrated a threshold of 7.7 $\mathrm{ng} / \mathrm{mL}$ with $78 \%$ sensitivity and $76 \%$ specificity. These studies had parallel results with ours, corroborating the role of AMH in predicting the failure of follicle growth. The somewhat different thresholds of AMH level among studies were presumably related to the variation of the AMH kits used in those studies.

The AMH level has been known to be a factor related to the follicular fluid [20], as a higher AMH level in the follicles halts follicle development. This was demonstrated in a study using continuous low 
dose FSH recombinant therapy that resulted in a significantly decreased AMH level in the follicle. It was suggested that a decreased AMH level would lead to the suppression of the inhibitory mechanism in the follicle; thus it could then develop into a dominant follicle [11]. Amer et al. [19] reported that after laparoscopic ovarian diathermy, the AMH level in subjects with ovulation was $25 \%$ lower than subjects with no ovulation. This resulted from the break up of the follicles after a diathermic procedure. In addition, the study also found $15 \%$ reduction in the AMH level in the group receiving only CC [19]. Highly elevated AMH in follicular fluid from PCOS patients and not age-matched with normal controls is suggesting an intrinsic abnormality in the ovarian follicles themselves in PCOS, which could contribute to disordered folliculogenesis [22].

In comparison with a similarly designed study by Mahran et al. [20], our study differed in terms of CC administration. In our study, a 100 mg dose of CC was administered, while Mahran et al. provided 187 cycles of CC in a total of 60 patients, to whom CC was given gradually until a dose of $150 \mathrm{mg}$ was reached. The rate of successful ovulation was found to increase if $\mathrm{CC}$ was given continuously until six cycles or if the doses were increased [2,14]. Mahran et al. evaluated ovulation when the mid-luteal progesterone was $\geq 12 \mathrm{ng} / \mathrm{mL}$ and by a follicle tracking examination. Our study used only the follicle tracking method, which classified follicle size $>18 \mathrm{~mm}$ as the indicator of the ovulation process. This study conducted additional analyses of other variables. We found that variables such as age, infertility duration, $\mathrm{BMI}$, waist circumference, $25-\mathrm{OH}$ vitamin D level, and cigarette exposure did not determine the follicular growth. The amount of fiber intake was significantly different between groups ( $p=0.001$ ), so that the higher the fiber intake, the higher the successful rate of follicular growth.

The association of ovulation with nutrition was previously discussed in a study by Gaskins et al. [23]. That study suggested the correlation of a high fiber intake with an increase of ovulation rate $(p<0.001)$, although the study was not conducted in patients with PCOS [23].

The other variable that has been considered to play a role in the ovulation process in $\mathrm{PCOS}$ is $25-\mathrm{OH}$ vitamin $\mathrm{D}$. A recent study demonstrated that $60 \%$ to $75 \%$ of women with PCOS tended to have a $25-\mathrm{OH}$ vitamin D deficiency (deficiency defined as having $<20 \mathrm{ng} /$ $\mathrm{mL}$ of 25-OH vitamin D) [24]. This finding was similar to our result showing $94 \%$ women with PCOS had $25-\mathrm{OH}$ vitamin D $<20 \mathrm{ng} / \mathrm{mL}$, but we did not find any significant difference for vitamin $D$ levels between ovulation and not ovulation group.

Obesity has been known to be a factor affecting ovulation [5]. In a study by Imani et al. [6], the obese and non-obese subjects showed a significant difference in ovulation rate $(p<0.001)$. Another study proposed that weight reduction by diet modification would improve ovulation [25]. In this study there were equivalent results to these previous studies, indicating a BMI difference of $24.74 \mathrm{~kg} / \mathrm{m}^{2}$ in the successful follicular growth group and $26.76 \mathrm{~kg} / \mathrm{m}^{2}$ in the unsuccessful follicular growth group, although the difference was statistically insignificant $(p=0.2)$.

This study determined a threshold AMH level as a predictor of follicular growth failure following $\mathrm{CC}$ treatment. Despite the high sensitivity and specificity of the AMH threshold level (i.e., $8.58 \mathrm{ng} / \mathrm{mL}$ ), its clinical application would result in only $40 \%$ probability of having follicular growth. Consequently, the application of $\mathrm{AMH}$ as a predictor of follicular growth failure in patients with PCOS treated with CC seems to be most beneficial in specific populations, like patients with PCOS in Indonesia that are mostly lean, vitamin D deficient, and lacking in signs of hyperandrogenism. Our finding that fiber intake was an influential variable in predicting the successful follicular growth was interesting. However, calculating or estimating the daily amount of fiber intake in clinical settings would be complicated, and fiber intake would be unsuitable for predicting successful follicular growth. Therefore, it was considered as one component in the successful follicular growth probability table according to various AMH levels and as preliminary data for further studies. The patients' symptoms like oligoovulation or anovulation could be related to high cortisol level, or also high production of TSH and insulin, even though the clinical signs did not include hypercortisolism, high TSH levels, or glucose intolerance. We did not check the level of cortisol, TSH, and insulin, which is a weakness of this study. Further studies are needed to assess those variables in a normal population as a comparison to our study, to validate the predictors found in this study, and to observe thoroughly the effects of fiber intake on the follicular growth in patients with PCOS with a larger prospective cohort or randomized controlled trial.

In conclusion, this study found that AMH level was the potential predictor of follicular growth failure in patients with PCOS treated with CC. The threshold AMH level was $8.58 \mathrm{ng} / \mathrm{mL}$ with $78 \%$ sensitivity and $67 \%$ specificity (AUC, $0.75 ; 95 \% \mathrm{Cl}, 0.62-0.88$ ). Age, infertility duration, $\mathrm{BMI}$, waist circumference, $25-\mathrm{OH}$ vitamin $\mathrm{D}$ level, and cigarette exposure were not different between the two groups. There was a significant difference in fiber intake between the successful and unsuccessful follicular growth groups, which was $11.20 \pm 2.68 \mathrm{~g}$ and $8.47 \pm 2.77 \mathrm{~g}$, respectively.

\section{Conflict of interest}

No potential conflict of interest relevant to this article was reported. 


\section{Acknowledgments}

The authors of this research paper gratefully acknowledge Natasya Prameswari, Irene Sinta Febriana, Prasetio Adinugroho, Amalia Shadrina, and Mrs. Liana W. Sutanto for their assistance and advice in preparing this manuscript.

\section{References}

1. Hart R, Norman R. Polycystic ovarian syndrome: prognosis and outcomes. Best Pract Res Clin Obstet Gynaecol 2006;20:751-78.

2. Messinis IE. Ovulation induction: a mini review. Hum Reprod 2005;20:2688-97.

3. Balen A. Ovulation induction. Obstet Gynaecol Reprod Med 2004;14:261-8.

4. Ghobadi C, Nguyen TH, Lennard MS, Amer S, Rostami-Hodjegan A, Ledger WL. Evaluation of an existing nomogram for predicting the response to clomiphene citrate. Fertil Steril 2007;87:597602.

5. Eijkemans MJ, Imani B, Mulders AG, Habbema JD, Fauser BC. High singleton live birth rate following classical ovulation induction in normogonadotrophic anovulatory infertility (WHO 2). Hum Reprod 2003;18:2357-62.

6. Imani B, Eijkemans MJ, te Velde ER, Habbema JD, Fauser BC. Predictors of patients remaining anovulatory during clomiphene citrate induction of ovulation in normogonadotropic oligoamenorrheic infertility. J Clin Endocrinol Metab 1998;83:2361-5.

7. Kurabayashi T, Suzuki M, Fujita K, Murakawa H, Hasegawa I, Tanaka K. Prognostic factors for ovulatory response with clomiphene citrate in polycystic ovary syndrome. Eur J Obstet Gynecol Reprod Biol 2006;126:201-5.

8. Dumesic DA, Lesnick TG, Stassart JP, Ball GD, Wong A, Abbott DH. Intrafollicular antimullerian hormone levels predict follicle responsiveness to follicle-stimulating hormone (FSH) in normoandrogenic ovulatory women undergoing gonadotropin releasing-hormone analog/recombinant human FSH therapy for in vitro fertilization and embryo transfer. Fertil Steril 2009;92:217-21.

9. Mashiach R, Amit A, Hasson J, Amzalzg S, Almog B, Ben-Yosef D, et al. Follicular fluid levels of anti-Mullerian hormone as a predictor of oocyte maturation, fertilization rate, and embryonic development in patients with polycystic ovary syndrome. Fertil Steril 2010;93:2299-302.

10. Lee JR, Kim SH, Kim SM, Jee BC, Ku SY, Suh CS, et al. Follicular fluid anti-Mullerian hormone and inhibin B concentrations: comparison between gonadotropin-releasing hormone $(\mathrm{GnRH})$ agonist and GnRH antagonist cycles. Fertil Steril 2008;89:860-7.

11. Catteau-Jonard S, Pigny P, Reyss AC, Decanter C, Poncelet E, De- wailly D. Changes in serum anti-Mullerian hormone level during low-dose recombinant follicular-stimulating hormone therapy for anovulation in polycystic ovary syndrome. J Clin Endocrinol Metab 2007;92:4138-43.

12. El-Halawaty S, Rizk A, Kamal M, Aboulhassan M, Al-Sawah H, Noah $\mathrm{O}$, et al. Clinical significance of serum concentration of anti-Mullerian hormone in obese women with polycystic ovary syndrome. Reprod Biomed Online 2007;15:495-9.

13. World Health Organization. The Asia-Pacific perspective: redefining obesity and its treatment. Sydney: Health Communications Australia; 2000.

14. Messinis IE, Milingos SD. Current and future status of ovulation induction in polycystic ovary syndrome. Hum Reprod Update 1997;3:235-53.

15. Li L, Chen X, Mo Y, Chen Y, Wenig M, Yang D. Elevated serum antimullerian hormone in adolescent and young adult Chinese patients with polycystic ovary syndrome. Wien Klin Wochenschr 2010;122:519-24.

16. Piltonen T, Morin-Papunen L, Koivunen R, Perheentupa A, Ruokonen A, Tapanainen JS. Serum anti-Mullerian hormone levels remain high until late reproductive age and decrease during metformin therapy in women with polycystic ovary syndrome. Hum Reprod 2005;20:1820-6.

17. Iliodromiti S, Kelsey TW, Anderson RA, Nelson SM. Can anti-Mullerian hormone predict the diagnosis of polycystic ovary syndrome? A systematic review and meta-analysis of extracted data. J Clin Endocrinol Metab 2013;98:3332-40.

18. Sahmay S, Atakul N, Aydogan B, Aydin Y, Imamoglu M, Seyisoglu $\mathrm{H}$. Elevated serum levels of anti-Mullerian hormone can be introduced as a new diagnostic marker for polycystic ovary syndrome. Acta Obstet Gynecol Scand 2013;92:1369-74.

19. Amer SA, Li TC, Ledger WL. The value of measuring anti-Mullerian hormone in women with anovulatory polycystic ovary syndrome undergoing laparoscopic ovarian diathermy. Hum Reprod 2009;24:2760-6.

20. Mahran A, Abdelmeged A, El-Adawy AR, Eissa MK, Shaw RW, Amer SA. The predictive value of circulating anti-Mullerian hormone in women with polycystic ovarian syndrome receiving clomiphene citrate: a prospective observational study. J Clin Endocrinol Metab 2013;98:4170-5.

21. di Clemente N, Goxe B, Remy JJ, Cate RL, Josso N, Vigier B, et al. Inhibitory effect of AMH upon the expression of aromatase and LH receptors by cultured granulosa cells of rat and porcine immature ovaries. Endocrine 1994;2:553-8.

22. Das M, Gillott DJ, Saridogan E, Djahanbakhch O. Anti-Mullerian hormone is increased in follicular fluid from unstimulated ovaries in women with polycystic ovary syndrome. Hum Reprod 
2008;23:2122-6.

23. Gaskins AJ, Mumford SL, Zhang C, Wactawski-Wende J, Hovey $\mathrm{KM}$, Whitcomb BW, et al. Effect of daily fiber intake on reproductive function: the BioCycle Study. Am J Clin Nutr 2009;90:1061-9.

24. Thomson RL, Spedding S, Buckley JD. Vitamin D in the aetiology and management of polycystic ovary syndrome. Clin Endocrinol
(Oxf) 2012;77:343-50.

25. Crosignani PG, Colombo M, Vegetti W, Somigliana E, Gessati A, Ragni G. Overweight and obese anovulatory patients with polycystic ovaries: parallel improvements in anthropometric indices, ovarian physiology and fertility rate induced by diet. Hum Reprod 2003;18:1928-32. 